\title{
ABOUT INFLUENCE OF OPERATIONAL TEMPERATURES ON RELIABILITY OF OPERATION OF THE EQUIPMENT OF THERMAL POWER PLANTS
}

\author{
Yuliana K. Atroshenko ${ }^{1, *}$, Alena A. Bychkova ${ }^{1}$, and Vladimir S. Andyk ${ }^{1}$ \\ ${ }^{1}$ National Research Tomsk Polytechnic University, 634050 Tomsk, Russia
}

\begin{abstract}
The description of degree model of reliability of the heat power equipment in which as a factor of loading the working temperature of the equipment is used is provided, interval estimates of constant values of model are given. For a row of elements of constructions of boilers dependences of the relative increase in failure density are given by operation in the conditions of the increased temperatures for a long time.
\end{abstract}

\section{Introduction}

Reliability represents the complex index [1] characterizing properties of the equipment during the long time frame to save and reproduce working parameters in use. For the description of object properties from the point of view of its reliability indices are used [1]: faultlessness of operation, maintainability and other characteristics.

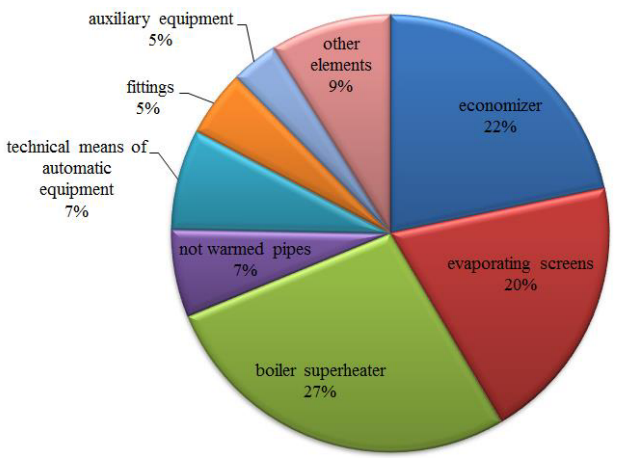

Fig. 1. The damaged elements of boiler aggregates.

Indices of reliability of the equipment substantially are defined by equipment operation modes (character and intensity of heat exchanging processes, burning, corrosion), depend on existence of deposits on surfaces and the processes proceeding in metals $[1,2]$. In operation of boiler aggregates surfaces of heating (fig. 1) are most subject to damages.

\footnotetext{
*Corresponding author: julie55@tpu.ru
} 
Pipes of furnace screens during an operating time are affected to radiative energy, corrosion influence of combustion products and other environments [2].

In the boiler installations working at supercritical parameters, pipes of radiation boiler superheaters are exposed to high-temperature corrosion which leads to changes in structure staly, to lowering of thermal stability and, finally, to thinning of pipes and appearance of bursts [2].

Thus, in use for extension of a resource of operation of the equipment and lowering of failure density special value has observance of the rules of operation including temperature condition.

\section{Reliability model}

Reliability of the equipment is characterized by numerical indices: time between failures, indices of readiness, maintainability, failure density, etc. Forecasting methods now in use of reliability are based on mathematical simulation of this parameter as functions from contributing factors. As temperature condition of operation exerts defining impact on reliability of the equipment, and corrupting, is generally caused, fatigue deformation, failure density can be defined by one-factor degree model [3]: $\operatorname{In}(T)=V \cdot T^{m}$,

where $V, m$ - constants, $T$ - a loading factor (working temperature of the equipment, K). Constants of $V$ and $m$ - experimentally defined values, they depend on material of the equipment and other parameters. As the known numerical values of constants of $V$ and $m$ for specific type of the equipment it isn't enough (for some elements such data generally are absent), the ranges of their change were defined.

Interval values of constants of $V$ and $m$ were defined, proceeding from the given conditions: the average operating time of the equipment on a failure makes $T o_{1}$ in case of normative value of working temperatures of the heat carrier $T_{1}$ (failure density in this case of $I n_{1}$ ), in case of increase in temperature up to $T_{2}$ value the time between failures decreases, and failure density increases and makes $I n_{l}$.

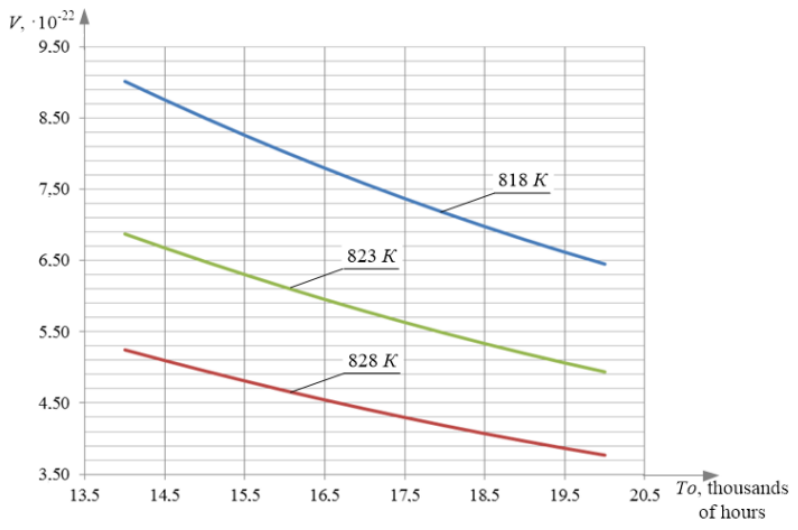

Fig. 2. Values of a constant of "V" for boiler superheaters boilers.

Based on the provided data $[4,5]$ it is possible to define value ranges of coefficients of $V$ and $m$ for different types of the equipment. Approximate values of a constant $V$ in working conditions of the boiler superheater at temperatures of 818-828 $\mathrm{K}$ can be determined by the dependences shown in a figure 2 . Values $\mathrm{m}$ in this case are in the range $5.79 \ldots 5.87$. 
Support of the normative mode of exploitation of boiler superheaters is defined by quality of operation of systems of regulation, and also systems of thermal protection and locks.

\section{Results and discussion}

During operation of the equipment summary time of its operation in case of raised (in relation to project values) temperatures can reach several tens hours. In a figure 3 the relative change of failure density of the boiler superheater of the boiler depending on the summary duration of operation at the uprated temperatures is shown.

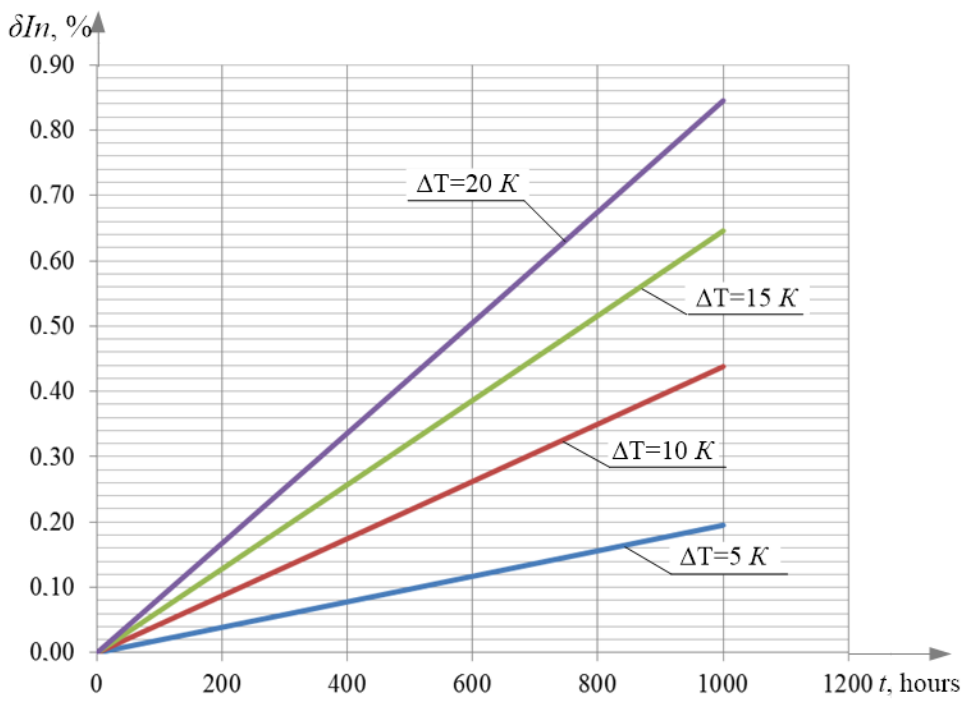

Fig. 3. Dependence of the relative increase in failure density of the boiler superheater by operation in the conditions of the increased temperature.

It is visible (fig. 3) that in the course of operation within 500 hours at a temperature exceeding estimated on $20 \mathrm{~K}$ change of failure density can reach $0.4 \%$, during operation of 1000 hours - to $0.85 \%$, etc. In this case authentic (exact) temperature measurement is important for implementation of its timely correction and/or actuating of protection in operation of the capital and ancillary equipment of thermal power plant as for the existing boiler installations having high rates of the worked-out park resource even little changes of failure density substantially increase probability of origin of alert conditions. It is connected to the fact that metal of elements of construction of a boiler in the course of the long operation in the conditions of high heat loads "accumulates" temperature fatigue, and sections of thinning of pipes appear. In such conditions even little relative change of failure density of the equipment can lead to alert conditions. Bursts in boiler superheaters are especially dangerous as until lowering of loading or break of a boiler (these processes can't instantaneous be executed) the depressurized section of the pipeline can significantly damage adjacent pipes of a packet and put the whole step of the boiler superheater out of action [2].

One of the major elements among ancillary equipment of boiler installations are smoke exhausters and forced draught fans. The average value of a time between failures for the forced draught fans is in the range of 23 thousand hours to 26 thousand hours, for smoke exhausters - in the range of 11 thousand hours to 14 thousand hours. It is connected to the fact that the smoke exhausters working with combustion gases with a temperature in the 
range from $423 \mathrm{~K}$ to $473 \mathrm{~K}$ are in "heavier" conditions in comparison with forced draught fans.

In a figure 4 the relative change of failure density the smoke exhausters and the forced draught fans boilers depending on the summary duration of operation is shown at the uprated temperatures of a work environment.

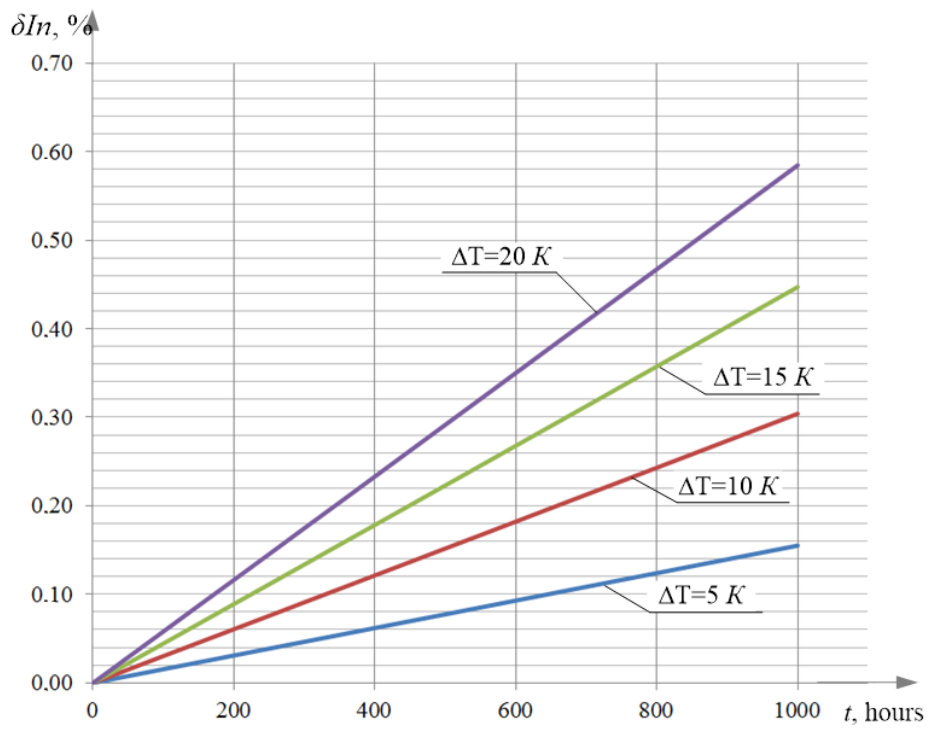

Fig. 4. Dependence of the relative increase in failure density the draft machines by operation in the conditions of the increased temperature.

It is visible (fig. 4) that in the course of operation within 600 hours at a temperature exceeding estimated on $20 \mathrm{~K}$ increase in failure density can reach $0.35 \%$. Therefore one of the main sources of failure the draft machines, is overheating of bearings. Insufficient quantity (or improper type) lubrications, the insufficient expenditure of the cooling water are basic reasons of origin of overheating of bearings. Timely detection of overheating of bearings will allow to prevent corrupting of the equipment.

\section{Conclusion}

The conducted researches showed that the summary operating time within 1000 hours of packets of the boiler superheater in the conditions of the increased temperatures leads to the relative increase in failure density up to $0.5 \%$. Such situations can arise owing to a high inertance of the thermoelectric transformers set in protective sleeves that leads to untimely response of systems of regulation to injection of cooling medium (feedwater, "own" condensate). Despite rather low values of increase in failure density (less than $1 \%$ ), growth of temperature of steam it is extremely unwanted since leads to the following consequences: excessive consumption of fuel, deterioration in a status of the equipment, stimulated actuating of systems of thermal protection.

The excessive consumption of fuel in case of not regulated increase in temperature of steam is caused by the fact that the management system fuel consumption of boiler installation connected to system of regulation of temperature of superheated steam will work out a signal on increase in fuel consumption for maintenance of the current temperature of steam. 
Lowering of utilization properties of the equipment is connected to temperature dependences of indices of reliability of operation of elements of the equipment, caused by lowering of thermal stability of steel, accumulation of temperature fatigue of metals and other factors which in total can promote origin of alert conditions. The received values are defined, proceeding from the forecast of operation of the equipment in a zone of "not regulated" temperatures within 1000 hours whereas in practice in case of operation of the equipment on the prolonged park resource this value can reach 3-4 thousand hours and more. In this case the relative increase in failure density will make $1-2 \%$.

\section{Acknowledgments}

This work with intensive heat and mass transfer processes at the geterogenius system was supported by the Russian Foundation for Basic Research (No. 14-08-00057). The work at the field of modeling of heat and mass transfer processes near boundary "liquid - gas" was supported by the scientific schools grant NSH-7538-2016.8.

\section{References}

1. A.P. Lashitskij, G.P. Sutotskij, G.V. Vasilenko, V.M. Evtushenko, Zhongguo Gonglu Xuebao 11, 4 (1998)

2. A.I. Andryushchenko, Reliability of the heat power equipment of TPP and NPP (Higher school Publ., Moscow, 1991) [in Russian]

3. V.V. Moskvichev, N.A. Makhutov, A.P. Chernyaev, Resistance to cracks and mechanical properties of constructional materials of technical systems (Science Publ., Novosibirskm, 2005) [in Russian]

4. GOST 28269-89 Stationary boilers of big power. General technical requirements and test methods, Moscow (2009) [in Russian]

5. SO 153-34.17.470-2003 The instruction about an order of inspection and extension of service life of steam lines over a park resource, Moscow (2003) [in Russian] 